\title{
Re : Tattoos: could they be used to advantage as a medical alert in oral and maxillofacial surgery?
}

Kluger, N.

2017-05

Kluger , N 2017 , ' Re : Tattoos: could they be used to advantage as a medical alert in oral and maxillofacial surgery? ' , British Journal of Oral and Maxillofacial Surgery , vol. 55 , no. 4 , pp. 439-439 . https://doi.org/10.1016/j.bjoms.2016.10.016

http://hdl.handle.net/10138/297789

https://doi.org/10.1016/j.bjoms.2016.10.016

publishedVersion

Downloaded from Helda, University of Helsinki institutional repository.

This is an electronic reprint of the original article.

This reprint may differ from the original in pagination and typographic detail.

Please cite the original version. 


\section{Letter to the Editor}

\section{Re: Tattoos: could they be used to advantage as a medical alert in oral and maxillofacial surgery?}

Sir

I read with interest the article by Colbert and Brennan published recently in the journal about the possible medical use of tattoos to alert healthcare professionals of life-threatening conditions in patients who might not be in a condition to express themselves. ${ }^{1}$ However, I was astonished that the authors stated that they failed to find other reports of their use. The use of medical alert tattoos has been known for a long time and we published a complete review on that topic in $2013 .^{2}$

If we ignore the long-term use of tattooing by the military for identification of blood groups, the first case reports of medical alert tattoos were published at the beginning of the 2000s, about patients with diabetes and adverse reactions to drugs such as succinylcholine or penicillin. ${ }^{2}$ To my knowledge, the most representative group of patients is the one with diabetes. Indeed, they tend to get tattooed either on the wrist or on the chest to warn about their condition to prevent the misdiagnosis of symptoms of hypoglycaemia. ${ }^{2,3}$ Bracelets are a hassle for some of them or do not fit their life style. ${ }^{3}$

Of course, medical alert tattoos are not restricted to diabetes or drug allergies. Virtually any condition, common or rare, can be tattooed. A quick look on the internet using search engines or social networks illustrates the widespread extent of this practice (for example, Addison's disease, hypopituitarism, or epilepsy). A Finnish anaesthesiologist has had his own organ donor card tattooed on his chest. ${ }^{4}$ Those tattoos also have other functions such as to raise awareness of one's condition, to gain peer-support, or to improve the patient's own body image. 2,3

Patients did not wait for us, physicians, to get their medical alert tattoos. However, a simple, easily-readable design and a rapidly accessible location should be advocated to make a medical alert tattoo useful in emergencies. The only restriction I would make is that only adults should get such tattoos after making a careful decision, and children should not be tattooed to alleviate the stress of their parents. ${ }^{5}$

\section{Conflict of interest}

I have no conflicts of interest.

\section{Ethics statement/confirmation of patients' permission}

Not applicable.

\section{References}

1. Colbert SD, Brennan PA. Tattoos: could they be used to advantage as a medical alert in oral and maxillofacial surgery? Br J Oral Maxillofac Surg 2017; 55:445

2. Kluger N, Aldasouqi S. A new purpose for tattoos: medical alert tattoos. Presse Med 2013;42:134-7.

3. Kluger N, Aldasouqi S. The motivations and benefits of medical alert tattoos in patients with diabetes. Endocrine Practice 2013;19:373-6.

4. Kämäräinen $A$, Länkimäki S. A tattooed consent for organ donation. Resuscitation 2009;80:284-5.

5. Chadwick S, Shah M. Tattoos: ancient body art may assist in medical emergencies. Eur J Pediatr 2013;172:995.

N. Kluger

Helsinki University Central Hospital and University of Helsinki, dermatology, venereology and allergology, Meilahdentie 2, PO BOX 16000029 HUS E-mail address: nicolas.kluger@hus.fi Available online 9 November 2016 